\title{
Tailings Dust Characterization and Impacts on Surface Water Chemistry
}

\author{
AMY CLEAVER, MSC ${ }^{1}$, HEATHER E. JAMIESON ${ }^{2}$, \\ CARRIE RICKWOOD $^{1}$ AND PHILIPPA HUNTSMAN ${ }^{1}$
}

${ }^{1}$ Natural Resources Canada

${ }^{2}$ Queen's University

Presenting Author: amy.cleaver@canada.ca

The increased potential for dust mobilization as a result of climate change indicates a need to better understand interactions between dust and surface water. This study investigated the geochemical effects of tailings dust on surface waters near Stirling mine, Nova Scotia. Tailings were sieved to $<63 \mu \mathrm{m}$ as a proxy for dust and characterized geochemically and mineralogically. Identification of both primary and secondary metal-bearing phases was achieved using a scanning electron microscope with automated mineralogy, electron microprobe analysis and synchrotron-based microanalysis. Shake flask tests were conducted in simulated stream waters $(\mathrm{pH}=7)$ to investigate the solubility of the metal-hosting mineral phases within the dust. Results indicate metal leaching at near neutral $\mathrm{pH}$ conditions. Sphalerite, cerussite and chalcopyrite are likely the main sources of $\mathrm{Zn}, \mathrm{Pb}$, and $\mathrm{Cu}$ in the shake flask leachate, based on calculated saturated indices and mass balance determined using PHREEQC modelling. Analyses of stream waters indicate similar conditions ( $\mathrm{pH}, \mathrm{ORP}$, saturation indices etc.) compared to the results of the shake flask tests. As a result, shake flask tests likely provide reasonable insight about processes occurring in the field, and tailings dust generated at the site is potentially a source of metals to surface waters (Cleaver et al. 2021).

[1] Cleaver, A., Jamieson, H., Rickwood, C., \& Huntsman, P. 2021. Tailings Dust Characterization and Impacts on Surface Water Chemistry at an Abandoned $\mathrm{Zn}-\mathrm{Pb}-\mathrm{Cu}-\mathrm{Au}-\mathrm{Ag}$ Deposit. Applied Geochemistry, Accepted. 